\title{
PSI-based methodology to land subsidence mechanism recognition
}

\author{
R. Bonì ${ }^{1}$, C. Meisina ${ }^{1}$, C. Perotti ${ }^{1}$, and F. Fenaroli ${ }^{2}$ \\ ${ }^{1}$ Department of Earth and Environmental Sciences, University of Pavia, Via Ferrata 1, 27100 Pavia, Italy \\ ${ }^{2}$ Studio Tecnico Fenaroli Fabio V. Mandalossa 3, 25055 Pisogne (BS), Italy \\ Correspondence to: R. Bonì (roberta.boni01@unipv.it) \\ Published: 12 November 2015
}

\begin{abstract}
A methodology based on Persistent Scatterer Interferometry (PSI) is proposed in order to disentangle the contribution of different processes that act at different spatio-temporal scales in land subsidence (i.e. vadose zone processes as swelling/shrinkage of clay soils, soil consolidation and fluid extraction). The methodology was applied in different Italian geological contexts characterized by natural and anthropic processes (i.e. a Prealpine valley and the Po Plain in northern Italy).
\end{abstract}

\section{Introduction}

Persistent Scatterer Interferometry (PSI) technique has significantly upgraded our ability to detect and quantify the land subsidence over wide areas. However the PSI technique shows two main limitations: (1) the PSI measurements represent the cumulative ground movements (natural plus anthropic and superficial plus deep displacements); therefore, the overlapping of several causes may make difficult the interpretation of ground deformation processes; (2) most of the geological processes are non-linear with seasonal and multiyear components, which are difficult to identify only through the use of the average rate of displacements $V_{\text {LOS }}$ (velocity along the Line of Sight). This work presents a methodology to analyse the ground deformations in order to disentangle the contribution of different processes that act at different spatio-temporal scales (i.e. swelling/shrinkage of clay soils, soil consolidation and fluid extraction), by the integration of PSI data and ground-based measurements.

\section{Study areas}

Two different geological contexts located in northern Italy and characterized by natural and anthropic processes were analysed: a Prealpine valley and a sector of the Po Plain (Figs. 1 and 2).
The Valley bottom of the Oglio River $\left(50 \mathrm{~km}^{2}\right)$ is located upstream the Iseo Lake and it is constituted by alluvial deposits (silt-sand, clay and sand-gravel layers) on Southalpine basement. This area is susceptible to subsidence processes, being, since the 1980, a high-urbanized area over unconsolidated alluvial materials.

The plain sector of the Oltrepo Pavese corresponds to the Southern and Central sector of the Po River Plain, with an extension of about $443 \mathrm{~km}^{2}$. The Quaternary cover consists in the succession of impermeable sediments (silt and clay) and more permeable horizons (gravels and sandy). The area is particularly vulnerable to swelling/shrinkage of the clayey soils, subsidence due to ground water pumping and to natural consolidation of soft soils.

\section{PSI datasets}

PSI data elaborated by Tele-Rilevamento Europa (T.R.E.) using images acquired by ERS 1-2 (1992-2000) and RADARSAT (2003-2010) satellites were used. The datasets of the Valley bottom of the Oglio River were processed with PSInSAR $^{\mathrm{TM}}$ technique and the Po Plain datasets with the SqueeSAR $^{\mathrm{TM}}$ technique. The PSInSAR ${ }^{\mathrm{TM}}$ technique allows to obtain high resolution displacement measurements from individual radar reflectors or Persistent Scatterers (PS) like anthropic structure or rocks, the SqueeSAR ${ }^{\mathrm{TM}}$ technique per- 

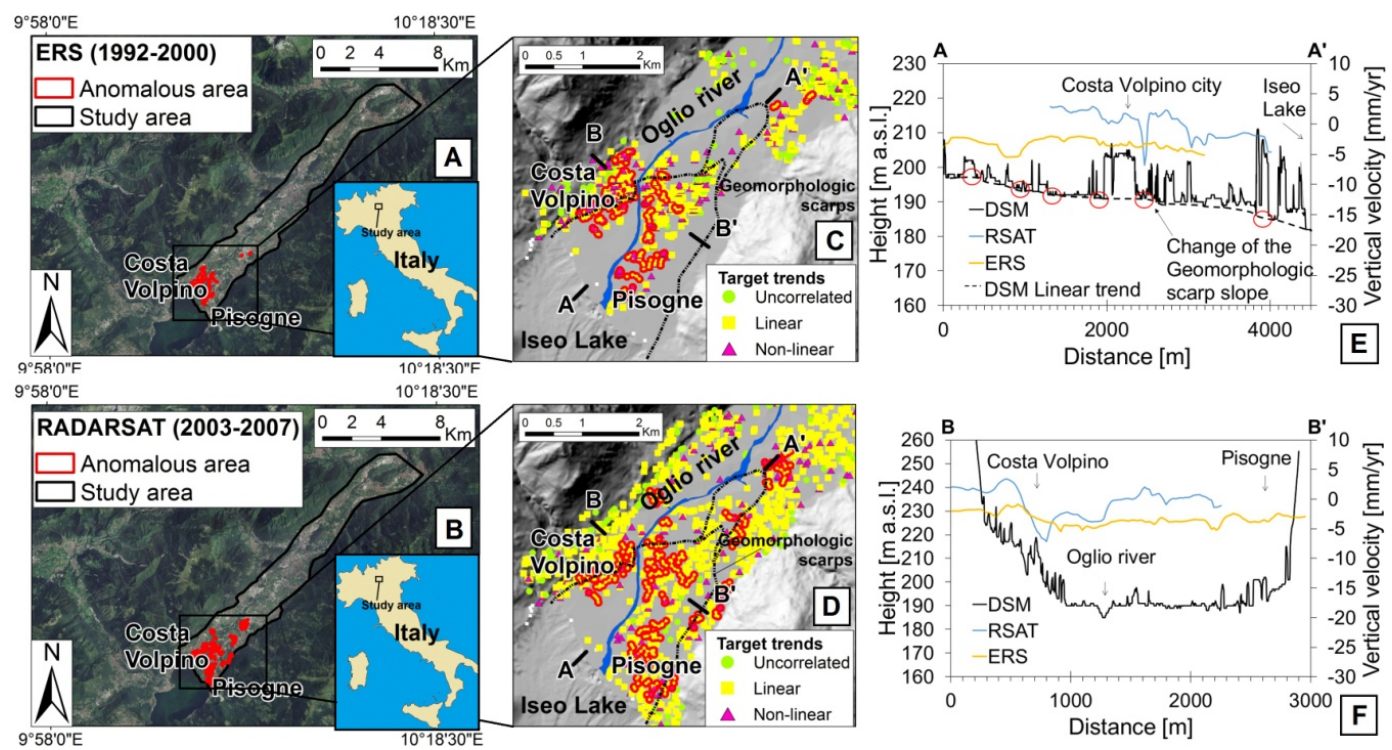

Figure 1. Anomalous areas detected by ERS descending (a) and RADARSAT descending (b). Target trends of ERS (c) and RADARSAT (d) dataset, and Digital surface model (DSM) of the Valley bottom of the Oglio river. Cross sections along the A-A' (e) and B-B' (f) sections of the ERS and RADARSAT (RSAT) datasets.
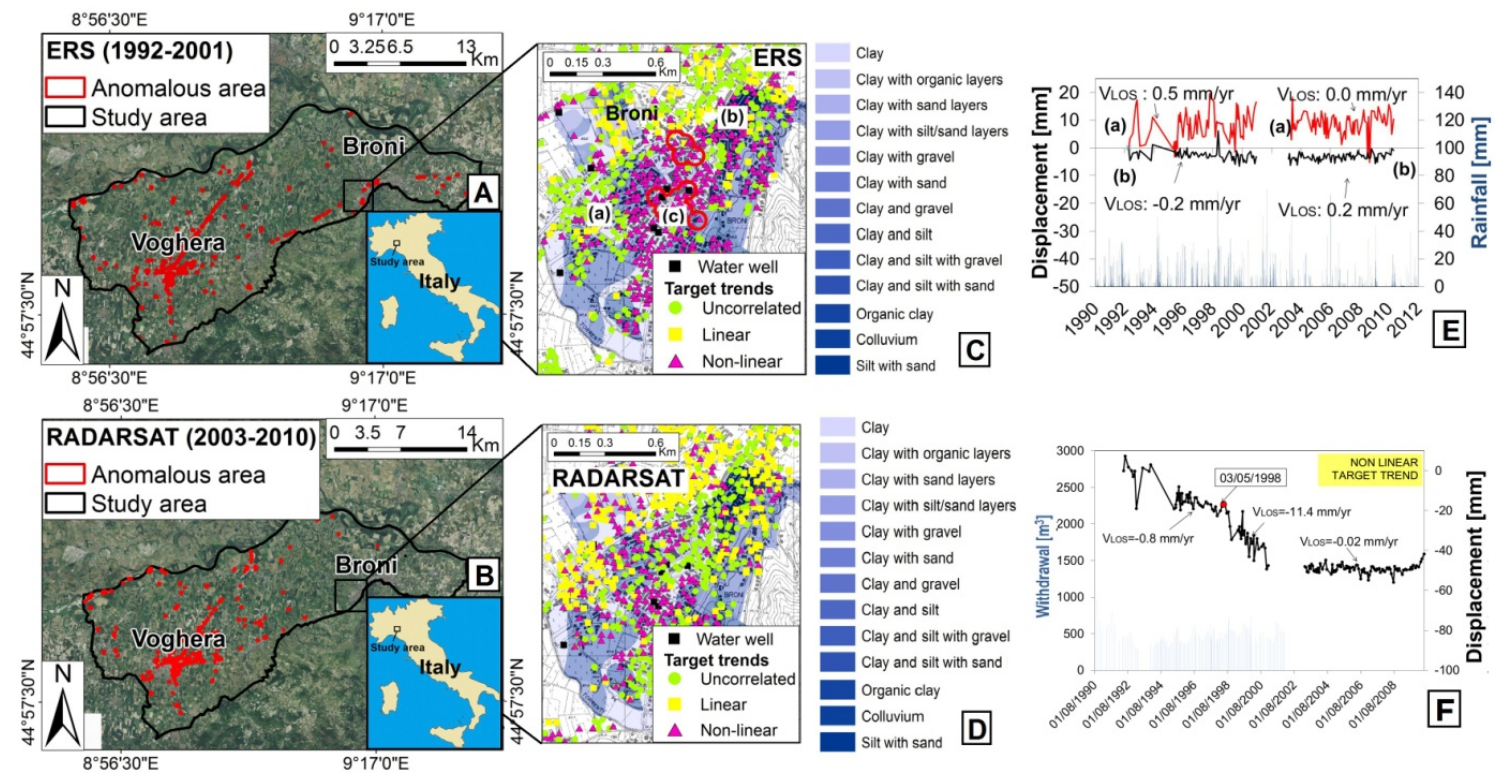

Figure 2. Anomalous areas detected by ERS descending (a) and RADARSAT ascending (b). Target trends of ERS (c) and RADARSAT (d) dataset, and lithological map of Broni town. TS of ERS and RADARSAT datasets at the location a, b compared with daily rainfall (e). Comparison of TS at location $\mathrm{c}$ and the groundwater exploitation (f).

mits to obtain measures also from distributed scatterers (DS) like sparse vegetated areas (Ferretti et al., 2011).

\section{Methodology}

The procedure is divided into three steps: (1) post-processing elaborations (2) characterization of ground motion areas (3) mechanism recognition.
Deformation accuracy assessment was carried out during the first step; the stable velocity range, the vertical and horizontal components of the motion were identified. The quality of Times Series was improved and possible errors (anomalous estimates not related to real ground motion) were corrected adopting the methodology of Notti et al. (2015). Thus, in a second step, the identification of the ground motion areas was performed using spatial clustering based of the unsta- 
ble $V_{\mathrm{LOS}}$ (anomalous areas). Trends (i.e. uncorrelated, linear, non-linear) of deformation time series (TS) were recognized by the application of the Automated Classification of Persistent Scatterers Interferometry time-series (Berti et al., 2013). Selecting the unstable linear time series, the frequency distribution of the LOS velocity was analysed and normal populations were separated through the expectation-maximization algorithm for mixtures of univariate normal function (Benaglia et al., 2009) in order to distinguish linear processes triggered by different causes (i.e. natural and anthropic).

At the third step, the PSI data were compared to predisposing (i.e. soft soil thickness geological and geotechnical model) and triggering factors (i.e. piezometric level variations etc.). Moreover, seasonal component of motion were analyzed at detailed scale; considering detrended deformation time series.

\subsection{Post-processing elaborations}

The velocity threshold was assessed considering the twice of the standard deviation of the PS/DS with the higher coherence (>0.8-0.9) and a common stability threshold was set to $\pm 2 \mathrm{~mm} \mathrm{yr}^{-1}$ for the PSI datasets over the Prealpine valley and $\pm 1.5 \mathrm{~mm} \mathrm{yr}^{-1}$ for the plain area of Oltrepo Pavese. The movements are mainly vertical in both the study areas. Only in the Po Plain datasets, anomalous displacements were detected on the 9 March 1997 and 16 July 2000 (ERS dataset), and on 10 December 2008 scene (RADARSAT dataset). The last RADARSAT (RSAT) anomalous values might be related to snowfall occurred on the day of the Synthetic Aperture Radar (SAR) acquisition.

\subsection{Characterization of the subsidence areas}

Spatial clustering analysis based on the unstable $V_{\text {LOS }}$ allows to detect in the Prealpine valley 17 and 31 anomalous areas (around 1-1.5 $\mathrm{km}^{2}$ ) in the time span 1992-2000 and 20032010, respectively (Fig. 1a and b). In the Po Plain, 117 and 122 anomalous areas (around $7 \mathrm{~km}^{2}$ ) were identified in the time span 1992-2001 and 2003-2010 (Fig. 2a and b).

Most of unstable TS of the Prealpine valley have linear trends (Fig. 1c and d). The $V_{\text {LOS }}$ ranges from -2 to $-8 \mathrm{~mm} \mathrm{yr}^{-1}$ in the period $1992-2000$ and from -2 to $-10 \mathrm{~mm} \mathrm{yr}^{-1}$ in the period 2003-2010.

In the Po Plain the $51 \%$ (ERS) and $50 \%$ (RSAT) of unstable TS show non-linear trends within the range from -6.6 to $-1.5 \mathrm{~mm} \mathrm{yr}^{-1}$ in the time interval $1992-2001$, and from -7 to $-1.5 \mathrm{~mm} \mathrm{yr}^{-1}$ in the period 2003-2010. The unstable linear TS show values within the range from -8 to $-1.5 \mathrm{~mm} \mathrm{yr}^{-1}$ (ERS) and from -7 to $-1.5 \mathrm{~mm} \mathrm{yr}^{-1}$ (RSAT) in the monitored periods (Fig. 2c and d).

Local ground motions triggered by anthropic processes (i.e. external load due to new buildings with $V_{\text {LOS }}$ between -3 and $-13 \mathrm{~mm} \mathrm{yr}^{-1}$ ) were recognized. In addition, the spatial distribution of the nonlinear TS in the Po Plain displays break dates in the ERS dataset (after 3 May 1998) and in the RSAT dataset (31 August 2009) related to wet and dry periods.

\subsection{Mechanism recognition}

The spatio-temporal analysis at large scale allowed to identify main ground motion areas located at Costa Volpino and Pisogne towns in the first test site and Voghera and Broni towns at the second one, where we carried out detailed analysis.

Different natural control mechanisms (i.e. water level fluctuation of the Iseo Lake, thickness of unconsolidated alluvial sediments) were analyzed to understand the displacements of the valley bottom of the Oglio River. The analysis highlights the geomorphologic control of the subsidence pattern; the stronger subsidence rate occurs in correspondence to a slope change (Fig. 1e and f). Subsidence due to dissolution of evaporitic rocks will also be investigated.

The comparison of the TS with the geological model of the Po Plain shows that the time series characterized by stable velocity detains seasonal component of motion (seasonal amplitude is about $10 \mathrm{~mm}$ ) where clay deposits are found (Fig. 2e). Subsidence areas due to groundwater exploitation were identified in the 1992-2001 period, (maximum $V_{\mathrm{LOS}}=-5 \mathrm{~mm} \mathrm{yr}^{-1}$ ); after 2003 (RSAT dataset) the decrease of groundwater pumping results in a decreasing trend of motion (Fig. 2f).

\section{Conclusions}

A new methodology based on PSI data was developed and validated in various geological contexts. The procedure allowed to identify multiyear (groundwater pumping, construction of new buildings, consolidation of soft soils, geomorphological processes) and seasonal (volume change of clay soils, groundwater oscillations) ground movements and proved to be an efficient tool for distinguish different anthropic and natural processes. The methodology can be used for land use planning and civil protection purposes.

Acknowledgements. The PSI data used in this work were provided by Regione Lombardia in the framework of the project "Interpretazione geologica e idrogeologica dei dati radar derivanti dal Piano Straordinario di Telerilevamento nazionale (PST) e da dati Radarsat con particolare riferimento alle province di Lecco e Pavia" financially supported by Direzione Generale Protezione Civile Prevenzione e Polizia Locale dell'Istituto regionale di ricerca della Lombardia (IREA). 


\section{References}

Benaglia, T., Chauveau, D., Hunter, D. R., and Young, D.: "mixtools": an R package for analyzing finite mixture models, J. Statist. Software, 32, 1-29, 2009.

Berti, M., Corsini, A., Franceschini, S., and Iannacone, J. P.: Automated classification of Persistent Scatterers Interferometry time series, Nat. Hazards Earth Syst. Sci., 13, 1945-1958, doi:10.5194/nhess-13-1945-2013, 2013.
Ferretti, A., Fumagalli, A., Novali, F., Prati, C., Rocca, F., and Rucci, A.: A new algorithm for processing interferometric data-stacks: SqueeSAR. Geoscience and Remote Sensing, IEEE Transactions on, 49, 3460-3470, 2011.

Notti, D., Calò, F., Cigna, F., Manunta, M., Herrera, G., Berti, M., Meisina, C., Tapete, D., and Zucca, F.: A User-Oriented Methodology for DInSAR Time Series Analysis and Interpretation: Landslides and Subsidence Case Studies, Pure Appl. Geophys., 1-25, doi:10.1007/s00024-015-1071-4, 2015. 